\title{
Investment and Interest Rate Policy
}

\author{
Bill Dupor*
}

\begin{abstract}
The paper's theorems reverse two standard results of New Keynesian economics simply by appending endogenous investment to a benchmark imperfect competition-sticky price model. Our results are: (a) a passive interest rate rule, where the monetary authority responds to inflation by lowering the real interest rate, implies local equilibrium uniqueness, whereas an active rule generates either indeterminacy or no equilibria locally; (b) a temporary, exogenous increase in the nominal interest rate causes a temporary increase in output and investment.
\end{abstract}

Existing research on interest rate policy in standard imperfect competitionsticky price models finds that an equilibrium is locally unique if the monetary authority follows an active rule, by responding to a one percentage point increase in inflation with a more than one percentage point increase in the nominal interest rate. ${ }^{1}$ Passive policy, where a one percentage point increase in inflation is met with a less than one percentage point increase in the nominal rate, generates equilibrium indeterminacy. Active policy, therefore, implies that the monetary authority increases the real interest rate in response to inflation while passive policy implies that the monetary authority decreases the real rate. A simple intuition for indeterminacy under a passive rule follows. If households expect high current inflation, the monetary authority responds by lowering the real rate.

*Assistant Professor of Finance, The Wharton School, University of Pennsylvania. Address: 2322 Steinberg Hall-Dietrich Hall, Philadelphia PA 19104-6367, (215) 898-7634, (215) 898-6200 FAX, dupor@wharton.upenn.edu. Part of this research was completed while the author was a Visiting Scholar at the Institute for Empirical Macroeconomics at the Federal Reserve Bank of Minneapolis, whose hospitality is appreciated. The author would like to thank Andrew Abel and Roger Farmer for helpful comments. This version: October 28, 1999.

${ }^{1}$ See Clarida, Galí and Gertler (1999), Kerr and King (1996), Rotemberg and Woodford (1997, 1998). Along similar lines, Christiano and Gust (1999) demonstrate equilibrium determinacy under active rules using a limited participation model. Important exceptions to this finding, based on either a productive role for money or a zero bound on the nominal interest rate, are developed in Benhabib, Schmitt-Grohé and Uribe (1999a, 1999b). 
In response, households reduce savings and increase desired consumption which leads firms to raise prices, thereby validating the original inflation expectations.

In these models, the interest rate affects output solely through the consumptionsavings decision of the household, and not though the investment decision of the firm. Work on these models typically ignores investment by assuming a fixed capital stock. ${ }^{2}$ With neoclassical investment, we show that uniqueness/determinacy results are reversed. Passive monetary policy ensures uniqueness and active policy leads to either indeterminacy or no equilibrium at all.

The basic idea relies on two relationships. First, no arbitrage between investment and government bonds implies that the capital rental rate must increase when the monetary authority raises the real interest rate on government bonds. Second, the capital rental rate satisfies

$$
r=\frac{M P K}{M}
$$

where $M P K$ is the marginal product of capital and $M$ is the gross markup. If households, in response to a sunspot, develop expectations of high current inflation, then the active monetary authority responds by increasing the real rate of return on government bonds. By (1), $r$ increases if either the marginal product of capital increases, due to an increase in labor, or the markup falls. Both of these responses tend to increase inflation, thereby validating the original inflation expectations. ${ }^{3}$

A second standard result in these models (without investment) is that an exogenous increase in the nominal rate contracts economic activity in the shortrun. Typically, the real rate moves in the same direction as the nominal rate. In this case, the household consumption-savings decision reduces output via the identical mechanism described above. With investment, however, if an increase in the nominal rate increases the real rate, equation (1) dictates a higher rental rate on capital requires either a higher $M P K$, and therefore employment, or lower $M$, and therefore less distortion associated with imperfect competition. Both of these effects are expansionary.

In the next section, we present and characterize the equilibria of a monetary neoclassical growth model with nominal rigidity. Section 2 studies the properties of equilibria under alternative nominal interest rate rules. In Section 3, we conclude with a discussion of why previous research has ignored investment.

\section{Investment in an Imperfect Competition-Sticky Price Model}

\section{Household-Firm Problem}

\footnotetext{
${ }^{2}$ For mainly theoretical papers that do not model investment, see Benhabib, Schmitt-Grohé and Uribe (1999a, 1999b), Dotesy, King and Wolman (1999), Rotemberg (1982). For mainly empirical papers that do not model investment see Christiano, Eichenbaum and Evans (1998), Claridia, Galí and Gertler (1999), Goodfriend and King (1997), Leeper and Sims (1994), McCallum and Nelson (1997, 1999), Rotemberg and Woodford (1997, 1998).

${ }^{3}$ This explanation gives only a flavor of the proof. Any explanation is incomplete unless we show that all of the equilibrium conditions are satisfied on the entire equilibrium path. We provide the complete analysis, which relies on saddle path arguments, in section 2 .
} 
The economy consists of a large number of identical household-firms, each of whom derives utility from consumption, real balances, not working and hitting a target rate of own price change according to

$$
\int_{0}^{\infty} e^{-\rho t}\left[\log (c)+\log (m)-n-\frac{\gamma}{2}\left(\frac{\dot{P}}{P}-\pi^{*}\right)^{2}\right] d t
$$

where $c, m, n$ denote consumption, real balances and labor supply. Also, $P$ denotes the dollar price that the household-firm charges for the good it sells and $\pi^{*}$ is the steady state net inflation rate. The cost of nominal price adjustment used here is based on Rotemberg (1982).

Households dislike having their price grow at a rate different from $\pi^{*}$. We assume separability between real balances and other arguments in (2), which minimizes the role of money in facilitating transactions. ${ }^{4}$ Each household is endowed with an initial quantity of capital $k_{0}$, non-capital wealth $s_{0}$ and a production technology.

The household-firm's instantaneous production technology is:

$$
y=\hat{k}^{\alpha} \hat{n}^{\beta}
$$

where $\hat{n}, \hat{k}$ denote the labor and capital hired by the household-firm. We assume $\alpha, \beta>0$ and $\alpha+\beta=1$.

Household-firms are subject to the constraint that given the price they charge $P$, sales are demand-determined:

$$
y=Y^{d} d\left(\frac{P}{\bar{P}}\right)
$$

where $\bar{P}$ is the economy-wide price level and $Y^{d}$ is aggregate output. This demand function may be derived using Dixit-Stiglitz preferences over differentiated goods. Let $d$ satisfy $d(1)=1, d^{\prime}(1)<-1$. For convenience, let $\phi=d^{\prime}(1)$ and $z=\phi /(\phi+1)>1$.

Household-firms may hold wealth as either capital or bonds. The law of motion for capital is

$$
\dot{k}=i-\delta k
$$

where $i$ denotes physical investment and capital depreciates at rate $\delta \in[0,1)$. The real value of non-capital wealth $s$ evolves according to:

$$
\dot{s}=(R-\pi) s-R m+\frac{P}{\bar{P}} y-w \hat{n}-r \hat{k}+r k+w n-i-c-\tau
$$

where $R$ denotes the nominal interest rate and $w, r$ denote real factor prices. Each household-firm has perfect foresight regarding and takes as given all prices (except the control variable $P$ ) and lump sum taxes $\tau$. Household-firms also face a lower bound on $s$.

\footnotetext{
${ }^{4}$ Seperability between $c$ and $m$ is one method of removing the distortionary effects of transactions money demand. See Woodford (1998) for a complete treatment.
} 
Taken together, the household chooses time paths for $c, i, s, m, n, k, \hat{n}, \hat{k}, P, y$ to maximize (2) subject to (3), (4), (5), (6) and a lower bound on $s$, taking as given $a_{0}, P_{0}$ and $k_{0}$ as well as the time paths for $\tau, R, Y^{d}$ and $\bar{P}$.

Substituting out $y$ using (3), the Hamiltonian is:

$$
\begin{aligned}
\mathcal{H}= & \log (c)+\log (m)-n-\frac{\gamma}{2}\left(\frac{\dot{P}}{P}-\pi^{*}\right)^{2}+\eta[i-\delta k]+\mu\left[Y^{d} d\left(\frac{P}{\bar{P}}\right)-\hat{k}^{\alpha} \hat{n}^{\beta}\right] \\
& +\lambda\left[(R-\pi) s-R m+\frac{P}{\bar{P}} \hat{k}^{\alpha} \hat{n}^{\beta}-w \hat{n}-r \hat{k}+r k+w n-i-c-\tau\right]
\end{aligned}
$$

The appendix contains a detailed derivation of the necessary conditions for optimization. Imposing these conditions, along with equilibrium symmetry $n=\hat{n}$, $k=\hat{k}, P=\bar{P}$, and market clearing, we have:

$$
\begin{gathered}
\dot{c}=c(R-\rho-\pi) \\
r-\delta=R-\pi \\
\beta r k=\alpha n c \\
\dot{\pi}=\rho\left(\pi-\pi^{*}\right)-(1+\phi) \frac{k^{\alpha} n^{\beta}}{\gamma c}+\frac{\phi n}{\gamma \beta} \\
\dot{k}=k^{\alpha} n^{\beta}-\delta k-c
\end{gathered}
$$

We will study equilibria close to a steady state; therefore, the transversality condition always holds.

Equation (7) is the standard consumption Euler equation. Equation (8) is a no-arbitrage condition between holding capital and government debt. Below we specify monetary policy as a nominal interest rate rule that responds to current inflation $R=\psi(\pi)$. Rearranging (8) under this policy, $r$ is inflation-determined:

$$
r=\psi(\pi)-\pi+\delta
$$

There is no equation (12) in the standard New Keynesian model because that model has no aggregate investment opportunities except for government bonds.

Equation (9) is an intratemporal equilibrium relationship between capital and labor share. Rearranging (9),

$$
r=\frac{\alpha n c}{\beta k}
$$

Note that $c=w$ because of our assumption on preferences. If the capital rental rate $r$ jumps upward at time zero due to a change in monetary policy through (12), then $n c$ must increase because $k$ cannot jump. Either $n$ or $c$ or both must increase. Compare this with the textbook IS-LM model. In standard IS-LM lingo, a higher real interest rate 'restricts aggregate demand' and reduces output and consumption. In this model, $n$ and/or $c$ must increase in the short-run if an equilibrium exists. Both of these responses are expansionary. 
To see this more clearly, note that the gross markup is $M=\beta y /(c n)$. Rearranging (9), we have

$$
r=\frac{1}{M}\left(\frac{\alpha y}{k}\right)
$$

The capital rental rate increases when the gross markup falls or the marginal product of capital (the term in parenthesis) increases. A fall in the markup is expansionary because markets are becoming more competitive. An increase in the marginal product of capital is also expansionary. In the short-run, capital does not adjust; therefore, the marginal product of capital can only increase by labor increasing.

Equation (10) is the household-firm Euler equation for choosing the inflation rate. Rearrange (10) to make the economics behind the pricing decision transparent. First,

$$
\dot{\pi}=\rho\left(\pi-\pi^{*}\right)-\theta
$$

where $\theta=\frac{\phi n}{\gamma \beta c}\left[\frac{1+\phi}{\phi} \beta k^{\alpha} n^{\beta-1}-c\right]$. Note that in the steady state, $M^{*}=\phi /(\phi+1)>$ 1. Using our expressions for $M$ and $M^{*}$,

$$
\theta=\frac{\phi y}{\gamma c}\left(\frac{M-M^{*}}{M M^{*}}\right)
$$

Solving (10) forward assuming $\pi^{*}=0$, we have

$$
\pi(t)=\int_{t}^{\infty} e^{-\rho(s-t)} \frac{\phi y(s)}{\gamma c(s)}\left(\frac{M(s)-M^{*}}{M(s) M^{*}}\right) d s
$$

If at time $t$, the actual markup is expected to be greater than the steady state markup in the future, then $M-M^{*}>0$. Since $\phi<0$, this implies $\pi(t)<0$. Firms cut prices because the markup is too high. A larger $\gamma$ implies inflation responds less to the markup being off its steady state. This slower response occurs because adjustment costs are higher. The marginal utility of consumption $1 / c$ enters the expression because equation (2) specifies a utility cost of price adjustment. Ceteris paribus, a higher marginal utility of consumption speeds up the adjustment of prices because the relative cost of price adjustment is low.

Notably absent from these expressions are the real value of household financial wealth $s$, the nominal price level $P$ and real money balances $m$. This absence is justified by the following considerations. First, we may safely ignore $s$ by assuming that the government adjusts lump sum taxes in a manner that keeps the government budget in balance at each instant. Second, we will be studying nominal interest rate rules which have a problem in uniquely determining the price level $P$ at each instant. This problem may be fixed by assuming the government follows a particular kind of fiscal policy. Third, since we study nominal interest rate rules and money is separable from consumption in the utility function, keeping track of $m$ will not be useful in finding the variables of interest.

\section{Monetary Policy}


The monetary authority sets the interest rate as a function of current inflation:

$$
R=\psi(\pi)
$$

Assume $\psi$ is non-decreasing, strictly positive and differentiable within a neighborhood of $\pi^{*}$. Examining equation (8), the real rate of return on capital net of depreciation $r-\delta$ must equal the real return on nominal bonds $R-\pi$. If the government is free to choose the steady-state nominal interest and inflation rates, the government would pin down the long-run return on capital. Money would be non-neutral in both the short and long run. We maintain long-run neutrality by requiring that

$$
\psi\left(\pi^{*}\right) \equiv r^{*}+\pi^{*}-\delta
$$

According to equation (42) in the appendix, in a steady state $r^{*}=\rho+\delta$. Furthermore, assume that there is only one value $\pi^{*}$ that solves (16) and that $\psi\left(\pi^{*}\right)>0$.

Next, substitute out $R, r, n$ to get the following system of differential equations

$$
\begin{gathered}
\dot{c}=c(\psi(\pi)-\rho-\pi) \\
\dot{\pi}=\rho\left(\pi-\pi^{*}\right)-\frac{(1+\phi)}{\gamma}\left(\frac{\beta}{\alpha}\right)^{\beta}\left(\frac{k}{c^{1+\beta}}\right)[\psi(\pi)+\delta-\pi]^{\beta}+\frac{\phi k}{\gamma \alpha c}[\psi(\pi)+\delta-\pi] \\
\dot{k}=k\left(\frac{\beta}{\alpha c}\right)^{\beta}[\psi(\pi)+\delta-\pi]^{\beta}-\delta k-c
\end{gathered}
$$

where $k_{0}$ is an initial condition.

\section{Local Dynamics}

For notational convenience, let

$$
\dot{\pi}=F(\pi, c, k) ; \dot{c}=G(\pi, c, k) ; \dot{k}=H(\pi, c, k)
$$

Letting $\hat{x} \equiv x-x^{*}$, the behavior of the system close to the steady state is given by

$$
\left[\begin{array}{l}
\dot{\pi} \\
\dot{c} \\
\dot{k}
\end{array}\right]=\left[\begin{array}{lll}
f_{1} & f_{2} & 0 \\
g_{1} & 0 & 0 \\
h_{1} & h_{2} & h_{3}
\end{array}\right]\left[\begin{array}{l}
\hat{\pi} \\
\hat{c} \\
\hat{k}
\end{array}\right]
$$

where we let $A$ denote the square matrix on the right-hand side of (20). Here, for example $f_{2}=\partial F(\pi, c, k) / \partial c$ evaluated at $\left(\pi^{*}, c^{*}, k^{*}\right)$. There is a unique steady state equilibrium with positive consumption and capital. ${ }^{5}$

\footnotetext{
${ }^{5}$ In the steady state,
}

$$
\begin{gathered}
c^{*}=\frac{\beta}{\alpha}\left(\frac{\alpha}{z}\right)^{1 / \beta}(\rho+\delta)^{(\beta-1) / \beta} \\
k^{*}=\frac{(\alpha / z)^{1 / \beta}(\beta / \alpha)(\rho+\delta)^{(\beta-1) / \beta}}{z(\rho+\delta) / \alpha-\delta}
\end{gathered}
$$

Note the absence in these expressions of underlying parameters relating to nominal variables: the aversion to inflation $\gamma$, nominal interest rate rule $\psi$ and inflation $\pi$. 
Next, we present the elements of $A$. We omit the derivations to conserve space

$$
\begin{gathered}
f_{1}=\rho-\left(\frac{\phi}{\alpha \gamma}\right) \frac{(\beta-1)\left[\psi^{\prime}\left(\pi^{*}\right)-1\right]}{[z(\rho+\delta)] / \alpha-\delta} \\
f_{2}=\frac{\beta \phi(\rho+\delta) k^{*}}{\alpha \gamma\left(c^{*}\right)^{2}}<0 \\
g_{1}=c^{*}\left(\psi^{\prime}\left(\pi^{*}\right)-1\right) \\
h_{1}=\frac{(\beta / \alpha)(\rho+\delta)^{\beta-1}(\alpha / z)^{(1-\beta) / \beta}\left[\psi^{\prime}\left(\pi^{*}\right)-1\right]}{z(\rho+\delta) / \alpha-\delta} \\
h_{2}=-\frac{z \beta(\rho+\delta)}{\alpha}\left(\frac{k^{*}}{c^{*}}\right)-1<0 \\
h_{3}=z(\rho+\delta) / \alpha-\delta>0
\end{gathered}
$$

Examining (20), the dynamics of $(\pi, c)$ are independent of the capital stock. The dynamic paths of inflation and consumption only depend upon the level of capital through the rental rate on capital; however, the capital rental rate is inflation-determined. This feature has two implications: (a) one eigenvalue of $(\pi, c, k)$ system is $h_{3}>0$; (b) the remaining two eigenvalues are determined by the upper left $2 \times 2$ submatrix of $A$ :

$$
\hat{A}=\left[\begin{array}{ll}
f_{1} & f_{2} \\
g_{1} & 0
\end{array}\right]
$$

Finally, the dynamics of $(\pi, c)$ are completely determined by $\hat{A}$.

\section{Interest Rate Rules}

Recent work in monetary economics has studied interest rate rules in models with nominal price rigidities. Rotemberg and Woodford $(1997,1998)$ and Clarida, Galí and Gertler (1999) stress that active monetary policy can rule out indeterminacy. ${ }^{6}$ A standard result in models without investment is that an active policy implies equilibrium uniqueness, while a passive policy gives rise to the possibility of expectations-driven fluctuations.

The intuition for indeterminacy under a passive policy without capital is straightforward. Imagine households believe that $\pi(0)>\pi^{*}$. At $t>0, \pi$ monotonically falls towards the steady state. Equation (17) governs the law of motion for consumption and implies that consumption must be decreasing if $\pi>\pi^{*}$. According to an analogue of equation (14), marginal revenue is less than marginal cost if inflation is above the steady state. This is consistent with

\footnotetext{
${ }^{6}$ Dupor (1999a) demonstrates that local uniqueness does not neccessarily imply global uniqueness under active policies in the standard imperfect competition-sticky price model.
} 
equilibrium if $c(0)>c^{*}$. As inflation falls to its steady state level, firms raise prices and households reduce consumption at a slower and slower rate.

Without capital, indeterminacy under an active policy cannot occur. Imagine households expect $\pi(0)>\pi^{*}$ and then $\pi$ monotonically falls towards the steady state. Active monetary policy implies $r>r^{*}$ and consumption is increasing as long as $\pi>\pi^{*}$. There is no local equilibrium path for consumption that supports these inflation expectations. If $c(0)>c^{*}$, then $c$ cannot approach the steady state because consumption is increasing over time. If $c(0)<c^{*}$, the goods market cannot be clearing over time because firms are increasing the markup and selling more goods. Diagram 1 provides the associated phase representation.

\subsection{Result 1: Only Passive Policies Imply Uniqueness}

Theorem 1 demonstrates that adding endogenous investment reverses these previous results.

Theorem 1: If $\psi^{\prime}\left(\pi^{*}\right)<1$, there exists a unique perfect foresight equilibrium in which $(\pi, c, k)$ converge asymptotically to the steady state $\left(\pi^{*}, c^{*}, k^{*}\right)$

Under a passive policy without capital, there is no third state variable $k$ and the dynamics of $(\pi, c)$ are qualitatively given by $\hat{A}^{7}$ In this case, the determinant of $\hat{A}$ is negative, and because $f_{1}>0$, the trace is positive. The local dynamics of $(\pi, c)$ are governed by one explosive and one non-explosive eigenvalue. Since both are jump variables, there is one-dimension of indeterminacy. See Diagram 2. Given an arbitrary $\pi(0)$, there exists a $c(0)$ and an equilibrium path for $(\pi, c)$ such that $(\pi, c) \rightarrow\left(\pi^{*}, c^{*}\right)$ asymptotically. On the diagram, $\mathcal{L}$ defines a locus of points $(\pi, c)$ consistent with a perfect foresight equilibrium (PFE).

With capital, this locus does not qualitatively change. Recall that the dynamic behavior of consumption and inflation does not depend on the capital stock since $\partial \dot{\pi} / \partial k=\partial \dot{c} / \partial k=0$. We do gain an initial condition $k(0)=k_{0}$ as well as the dynamic equation:

$$
\dot{k}=h_{1} \hat{\pi}+h_{2} \hat{c}+h_{3} \hat{k}
$$

Consider the phase diagram for system (20). There is no need to construct a three-dimensional phase diagram because the locus $\mathcal{L}$ defines $\hat{\pi}$ as a function of $\hat{c}$. The equilibrium dynamics of $(\pi, c, k)$ collapse to the two-variable system $(c, k)$.

$$
\begin{gathered}
\dot{c}=r_{1} \hat{c} \\
\dot{k}=\left(\frac{h_{1} r_{1}}{g_{1}}+h_{2}\right) \hat{c}+h_{3} \hat{k}
\end{gathered}
$$

Diagram 3 presents the phase space representation. The locus $\mathcal{W}$ gives $(c, k)$ pairs consistent with local stability. The initial condition $k_{0}$ then implies a unique $c(0)$ as well as an entire equilibrium path for the dynamic system.

\footnotetext{
${ }^{7}$ Under a passive policy, the differences between the model with and without capital do not change the signs of any element of $\hat{A}$ and therefore do not change the dynamics of $(\pi, c)$.
} 
Trying (unsuccessfully) to construct self-fulfilling expectational equilibria provides useful intuition for theorem 1 . For simplicity, assume the capital stock is at its steady state level $k_{0}=k^{*}$. Clearly, the steady state is an equilibrium. Are there other equilibria? Imagine households were to form expectations that $\pi(0)>\pi^{*}$. Examining diagram 2, this would be consistent with a local equilibrium for $(\pi, c)$ if consumption and inflation started above and monotonically fell towards the steady state.

Next consider the implication of this $(\pi, c)$ path for capital. First, above steady state consumption occurs at the expense of investment and therefore reduces capital accumulation. Second, above steady state inflation lowers the rental rate on capital under a passive policy. This is because a fall in the price of capital relative to labor leads household-firms to reduce labor input, which reduces output in equilibrium. Lower output reduces capital accumulation. Finally, once capital is below the steady-state because of inflation and consumption, low capital on its own reduces capital accumulation because output is increasing in capital. If $\pi(0)>\pi^{*}$, the capital stock falls away from the steady state. We have shown the impossibility of an equilibrium where $\pi(0)>\pi^{*}$ and the economy remains close to the steady state. Similarly if $\pi(0)<\pi^{*}$, the capital stock grows away from the steady state. Locally, the only equilibrium is the steady state.

While theorem 1 demonstrates that uniqueness always obtains under a passive rule, theorem 2 demonstrates that, in general, uniqueness does not obtain under an active rule.

Theorem 2: Under an active monetary policy:

(a) if $f_{1}>0$ and $k_{0} \neq k^{*}$, no PFE exist in which $(\pi, c, k)$ converge asymptotically to the steady state;

(b) if $f_{1}<0$, a continuum of PFE exist in which $(\pi, c, k)$ converge asymptotically to the steady state.

Consider part (a). If $f_{1}>0$ and policy is active, the dynamics of $(\pi, c)$ are governed by two explosive eigenvalues. Diagram 1 applies and the only equilibrium of the subsystem involves $(\pi(t), c(t))=\left(\pi^{*}, c^{*}\right)$ for all $t$. This equilibrium restriction on $(\pi(t), c(t))$ implies the dynamic equation for capital (27) becomes

$$
\dot{k}=h_{3} \hat{k}
$$

Since $h_{3}>0, k$ generically explodes over time. A local equilibrium obtains only in the special case that $k_{0}=k^{*}$.

Next, consider part (b) of theorem 2. The dynamics of inflation and the markup change dramatically when $f_{1}=\partial \dot{\pi} / \partial \pi<0$ under active rules. An alternative expression for (18) is

$$
\dot{\pi}=\rho\left(\pi-\pi^{*}\right)-\theta(\pi, c, k)
$$

where $\theta$ expresses the amount by which the markup is above its target. An 
illustrative expression for $\theta$ is

$$
\theta(\pi, c, k)=\frac{\phi k}{\gamma \alpha c}[\psi(\pi)+\delta-\pi]\left\{\frac{1+\phi}{\phi} \beta\left(\frac{\beta}{\alpha}\right)^{\beta-1} c^{-\beta}[\psi(\pi)+\delta-\pi]^{\beta-1}-1\right\}
$$

Imagine that $(\pi, c, k)$ are at the steady state and suddenly there is an increase in inflation. Under an active policy, the central bank responds by increasing the real interest rate $\psi(\pi)+\delta-\pi$. This raises the cost of production for firms. Labor input increases as firms move away from capital as a factor of production. In equilibrium, the $\{\cdot\}$ term becomes negative and the markup falls beneath the steady state level. Intuitively, a higher interest rate and larger capital costs reduce the markup. Since the markup is below the steady-state level, firms optimally respond by raising prices.

If the negative effect of the real interest rate on the markup is sufficiently strong, that is $\partial \theta\left(\pi^{*}, c^{*}, k^{*}\right) / \partial \pi>\rho$ or equivalently $f_{1}<0$, then active policy leads to equilibrium indeterminacy in the $(\pi, c)$-system. Imagine household-firms are at the steady state $k^{*}$ and adopt expectations of instantaneous inflation in the short run. Given an active interest rate rule, they also expect the central bank to raise the real rate in response to inflation. Higher capital costs drive the markup below the steady state level, inducing household-firms to raise prices. This realized inflation validates the household-firms' expectations. This indeterminacy in terms of $(\pi, c)$ is two-dimensional. Not only may household-firms have arbitrary, self-fulfilling expectations about initial inflation, household-firms may also have arbitrary, self-fulfilling expectations regarding time zero consumption.

In theorem 1 , one-dimensional indeterminacy in the $(\pi, c)$-system leads to local uniqueness in the three variable system. One degree of indeterminacy in the $(\pi, c)$-system is used to satisfy the initial condition for capital. Adding a second dimension of indeterminacy to the $(\pi, c)$-system leads to one-dimensional indeterminacy in the three variable system.

Constructing an example of a self-fulfilling inflationary equilibrium provides useful intuition for part (b) of theorem 2.

Experiment 1 Self-fulfilling inflation under active policy.

Consider a specific parameterization with active policy such that $f_{1}<0$. We choose $\rho$ for our quarterly model to imply an annual $1.8 \%$ discount rate. The response of the nominal interest rate to inflation is taken from Taylor (1993). The steady state inflation rate, which has no effect on the model dynamics, equals zero. We set $\alpha=0.3, \delta=0.05$, and $\phi$ so that the steady state gross markup is 1.05. Finally, our cost of price adjustment parameter is lower than in some existing studies. Increasing $\gamma$ substantially introduces complex eigenvalues into A. ${ }^{8}$

\footnotetext{
${ }^{8}$ Although complex eigenvalues do not change the determinacy properties of the model, they complicate understanding the dynamics of indeterminacy without adding additional insight.
} 


\begin{tabular}{|c|c|c|c|c|c|c|}
\hline$\gamma$ & $\alpha$ & $\delta$ & $\rho$ & $\pi^{*}$ & $\phi$ & $\psi^{\prime}\left(\pi^{*}\right)$ \\
\hline 100 & 0.3 & 0.05 & 0.0045 & 0 & -21 & 1.5 \\
\hline
\end{tabular}

Assume that capital begins at the steady state $k_{0}=k^{*}$. Trivially, there exists an equilibrium where $(\pi, c, k)$ remain at the steady state for all $t$. Next, we construct a second equilibrium. ${ }^{9}$ Let us conjecture an equilibrium where household-firms believe that $\pi(0)=0.01$, after which inflation falls until it hits zero at time $\hat{T}$. After time $\hat{T}$, inflation is negative with an inverted hump-shaped pattern, eventually asymptoting to zero from below. The inflation path is plotted in the upper panel of figure 1 , where $\hat{T} \cong 3$.
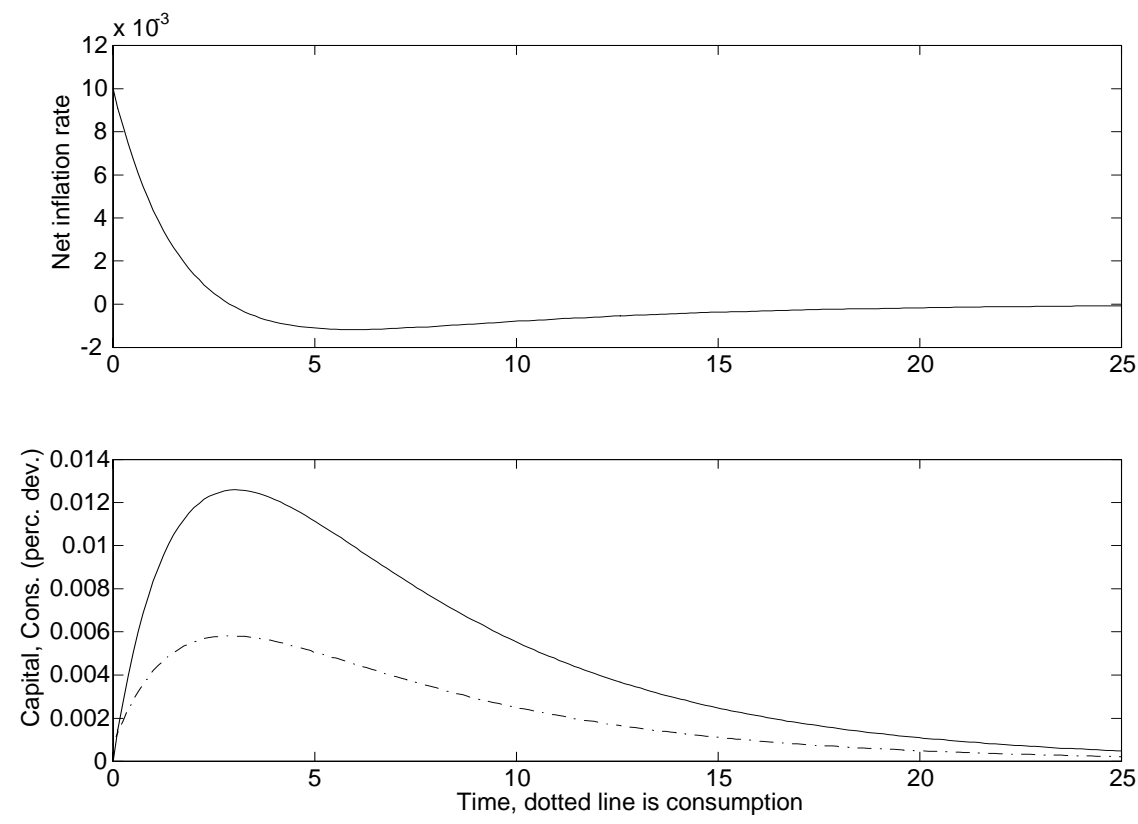

Figure 1: Self-fullfilling Inflation under Active Policy

Given this inflation path together with an active policy, the real interest rate is above the steady state for $t<\hat{T}$ and below the steady state for $t>\hat{T}$. In order for the consumption choice to be optimal, consumption must be increasing before time $\hat{T}$ and falling afterwards. The real interest rate path alone does not tell us what happens to initial consumption. Given our previous argument which established that inflation is expansionary, we conjecture $c(0)>c^{*}$. The consumption path is the dotted line in the lower panel of figure 1.

\footnotetext{
${ }^{9}$ For our parameterization,
}

$$
A=\left[\begin{array}{ccc}
-0.74 & -0.14 & 0 \\
0.68 & 0 & 0 \\
11.8 & -1.94 & 0.14
\end{array}\right]
$$

with eigenvalues $0.14,-0.16,-0.58$. 
Next, we must show that the implied path for aggregate consumption delivers a household-firm pricing rule that validates the conjectured inflation dynamics. Recall that $\theta$ measures the extent to which marginal revenue is above marginal cost. Note that if $\partial \theta / \partial \pi=0$, firms will raise prices rule if and only if consumption is expected to be above the steady state in the future. For example, $\partial \theta / \partial \pi=0$ if monetary policy is neutral $\psi^{\prime}(\pi)=1$, or if there is no capital in the model (see for example Clarida, Galí and Gertler (1999)). In general, $\partial \theta / \partial \pi \neq 0$ because inflation influences the real rate, which in turn affects marginal cost. In experiment 2, high inflation increases marginal cost because active policy implies a high capital rental rate. This explains why, contrary to a model without capital, the inflation path can be below the steady state while the consumption path is above the steady state, as is the case in experiment 2 for $t>\hat{T}$. Firms are cutting prices, $\pi(t)<0$, because the cost of capital is low. In theorem $2, f_{1}<0$ is required for indeterminacy. This inequality guarantees a sufficiently strong effect of inflation on marginal cost. Prior to time $\hat{T}$, inflation and consumption are both above their steady state values, which we have already shown is consistent with optimal household-firm pricing.
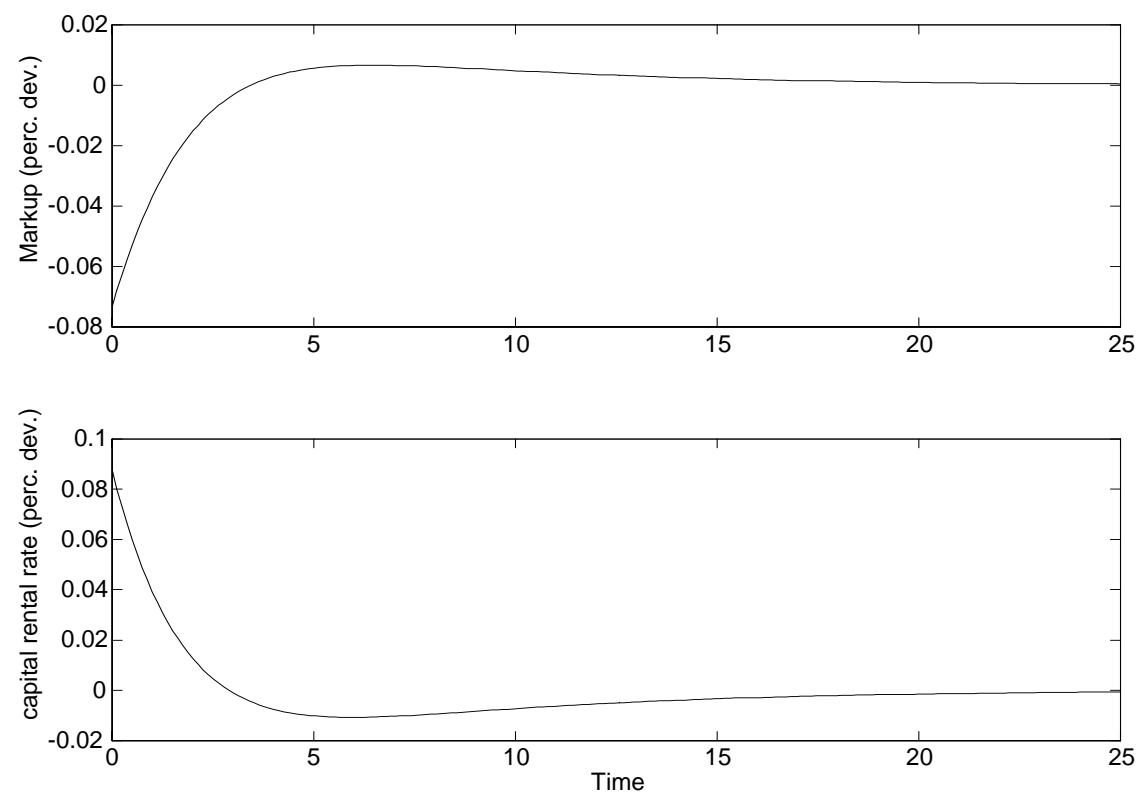

Figure 2: Self-fulfilling Inflation under Active Policy

Finally, consider capital dynamics. Clearly, above steady-state consumption for all $t$ comes at the expense of forgone investment. Lower investment reduces capital accumulation. Next, high initial inflation under an active policy implies a high real rate. This induces firms to increase labor input which increases output. High labor accounts for the initially increasing capital in the bottom panel of figure 1. Once capital is above the steady state, as explained previously, this 
tends to increase capital accumulation. At $t>\hat{T}$, consumption is above and inflation is below the steady state. Both consumption and inflation work to offset the positive effect on capital accumulation of the high level of the capital stock. Making these effects exactly offset requires an appropriate choice of $c(0)$, taking as given the arbitrary initial inflation we chose. This calculation of $c(0)$ is carried out in the appendix.

\subsection{Result 2: An Expansionary Interest Rate Hike}

Under a passive policy, the economy is sunspot-proof. To study dynamic responses, we introduce a deterministic disturbance to the interest rate rule.

Experiment 2 Exogenous short-term increase in $R$ under a passive policy.

Replace the time homogenous monetary rule (15) with

$$
R=\psi(\pi)+\varepsilon(t)
$$

where $\varepsilon(t)=\bar{\varepsilon} \exp (-\theta t)$ for $t \geq 0, \theta, \bar{\varepsilon}>0$. Assume $k(0)=k^{*}$ and households have perfect foresight regarding the $\varepsilon(t)$ path. The dynamics close to the steady state are:

$$
\left[\begin{array}{c}
\dot{\pi} \\
\dot{c} \\
\dot{k}
\end{array}\right]=\left[\begin{array}{lll}
f_{1} & f_{2} & 0 \\
g_{1} & 0 & 0 \\
h_{1} & h_{2} & h_{3}
\end{array}\right]\left[\begin{array}{l}
\hat{\pi} \\
\hat{c} \\
\hat{k}
\end{array}\right]+\left[\begin{array}{c}
\left(f_{1}-\rho\right) /\left[\psi^{\prime}\left(\pi^{*}\right)-1\right] \\
c^{*} \\
h_{1} /\left[\psi^{\prime}\left(\pi^{*}\right)-1\right]
\end{array}\right] \varepsilon(t)
$$

We set $\psi^{\prime}\left(\pi^{*}\right)=0.5, \bar{\varepsilon}=0.001$. The remaining parameters are identical to those in experiment 1.

Figure 3 plots the time path of $(\pi, c, k)$. In the standard New Keynesian model, an increase in the nominal interest rate increases the real rate. This increases private savings and reduces output. With investment, however, there is a short-run increase in investment and consumption in response to an increase in the nominal interest rate.

With flexible prices, an exogenous increase in the nominal rate would immediately lead to a one-for-one increase in the inflation rate. The capital rental rate and other real variables would be unaffected. Because household-firms dislike changing prices, however, the inflation rate does not adjust completely. Part of the interest rate hike is accounted for by a higher rental rate $r$. See Figure 4 .

Household-firms face a higher cost of production because $r$ increases. Householdfirms do not fully adjust prices immediately in response to the cost shock. This implies two things. First, firms would like to switch their input mix away from the more expensive capital at the new higher $r$ and towards the less expensive labor at the original steady state wage. In general equilibrium, this drives up both $w$ and $n$. Second, since firms do not completely adjust prices, the markup falls.

Several things change for households. First, greater labor income increases permanent income. Since the policy shock is temporary, the income increase is 

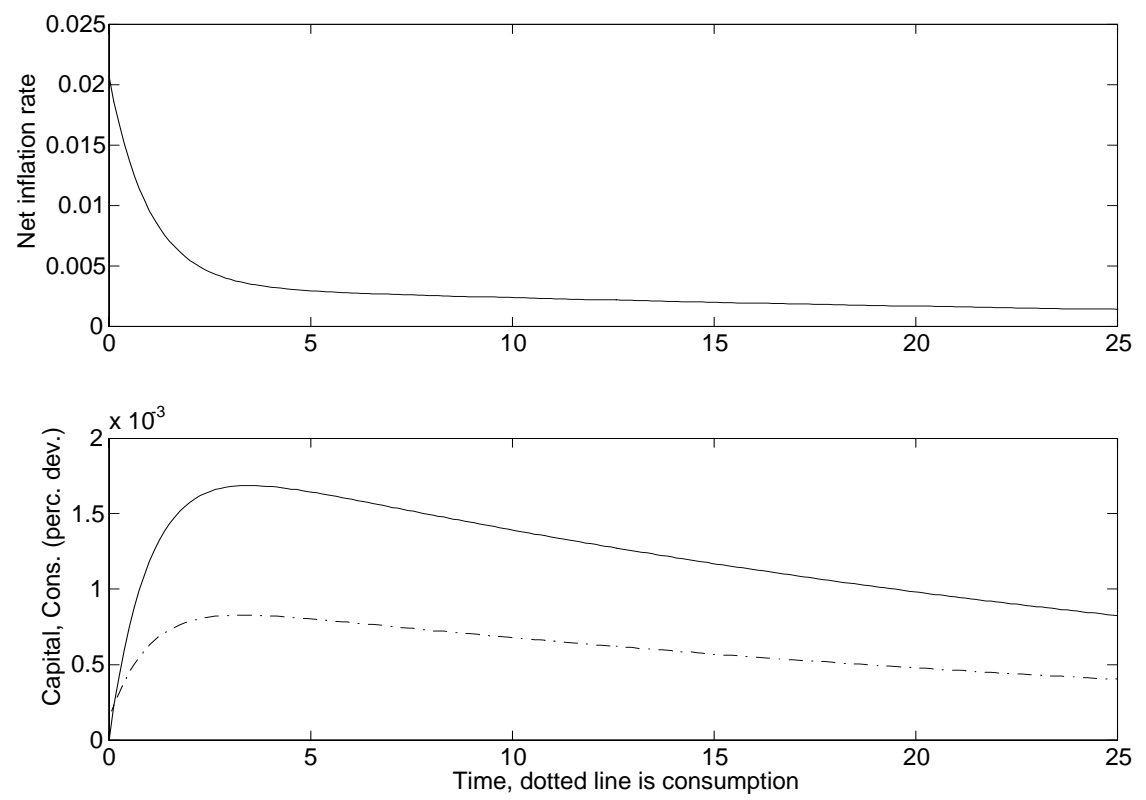

Figure 3: Nominal Interest Rate Hike under Passive Policy
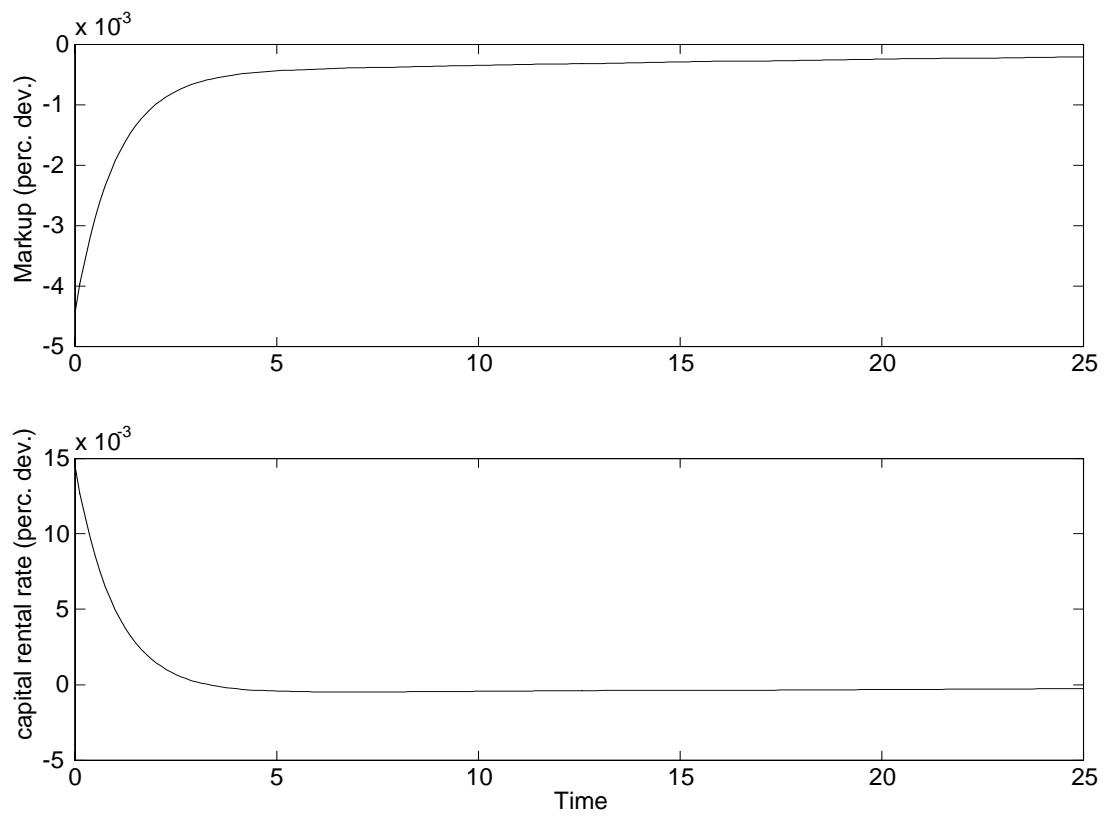

Figure 4: Nominal Interest Rate Hike under Passive Policy 
also temporary. Understanding that their fortune is fleeting, households increase savings to smooth consumption. With a fixed quantity of investment, a shift out in household-firms' savings would reduce $r$. Of course, we posited an equilibrium where $r$ increases. This is consistent with an increase in savings if investment also increases. Note that if household-firms forecast greater demand for goods, because the current situation is going to persist, this shifts out the investment curve, leading to a simultaneous increase in interest rates and investment. The solid line on the lower panel of Figure 3 gives the time path of capital. On impact, the capital stock, and therefore investment, grow above the steady state. Eventually, the nominal interest rate shock dissipates and the economy returns to the steady state.

\section{Conclusion}

Including a standard investment technology in a benchmark imperfect competitionsticky price model virtually reverses the properties of interest rate rules. It is natural to ask why researchers have not modelled investment. Ignoring investment in recent optimization-based sticky price models has mimicked the approach taken in many textbook IS-LM models. McCallum and Nelson $(1997$, p. 7) argue the case for ignoring investment: "there is very little connection at cyclical frequencies between capital stock movements and those in aggregate output and consumption variables. In large part this is because a typical year's investment is very small in relation to the existing stock of capital."

This reasoning misses the overwhelming rationale for modelling investmentin a forward looking model, a firm's current investment decision critically hinges on future demand conditions. Since investment is a significant fraction of GDP, this has important implications for aggregate output. Theoretical arguments aside, the fact that quarterly investment is more than four times as volatile as consumption in the post-war U.S. provides ample motivation for modelling investment!

In adding investment, we adopted a standard neoclassical model of capital accumulation. First, firms invest without adjustment costs, irreversibility or credit constraints. Apart from the markup, capital is paid its marginal product. Second, capital and government bonds are perfect substitutes traded in markets without any borrowing constraints. Given our interest rate rule, this implies that the marginal product of capital over the markup depends only on inflation. Adding credit market frictions and imperfect substitutability between capital and government debt will be the subject of future work. In preliminary work (Dupor 1999b), we show that indeterminacy under active rules easily obtains with empirically reasonable adjustment costs to aggregate investment. 


\section{Appendix: Derivations}

Derivation of Equilibrium Differential Equation: The first-order necessary conditions for household optimization by choice of $c, m, n, \hat{n}, \hat{k}, i, s, k$ and $P$ are:

$$
\begin{gathered}
\lambda=\frac{1}{c} \\
\lambda R=\frac{1}{m} \\
1=w \lambda \\
-\beta \mu \hat{k}^{\alpha} \hat{n}^{\beta-1}+\lambda \frac{P}{\bar{P}} \beta b \hat{k}^{\alpha} \hat{n}^{\beta-1}-\lambda w=0 \\
-\alpha \mu \hat{k}^{\alpha-1} \hat{n}^{\beta}+\lambda \frac{P}{\bar{P}} \alpha \hat{k}^{\alpha-1} \hat{n}^{\beta}-\lambda r=0 \\
\eta=\lambda \\
\dot{\lambda}=\lambda[\rho+\pi-R] \\
\dot{\eta}=\rho \eta+\delta \eta-r \lambda \\
\lambda \frac{P}{\bar{P}} \hat{k}^{\alpha} \hat{n}^{\beta}+\mu \frac{P}{\bar{P}} Y^{d} d^{\prime}\left(\frac{P}{\bar{P}}\right)=\gamma \rho\left(\pi-\pi^{*}\right)-\gamma \dot{\pi}
\end{gathered}
$$

as well as the transversality condition and (5) and (6) the laws of motion for $k$ and $s$.

We will study symmetric equilibria where $n=\hat{n}, k=\hat{k}, P=\bar{P}$ and $y=Y^{d}$. First, use equations (30), (32) and (35) to substitute out $\lambda, \eta$ and $w$. Furthermore, we will ignore the law of motion for debt (6) and behavior of $s$ because we shall study Ricardian monetary-fiscal policies. In addition, we will study monetary policies that take the form of interest rate rules. Since real balances are separable in the utility function, equation (31) will only determine the value of $m$ in equilibrium. Therefore, we ignore (31) since we are not interested in the behavior of real balances. Given the above considerations, the equilibrium conditions for consumer behavior and resource constraints in a symmetric equilibrium are:

$$
\begin{gathered}
\beta \mu \frac{y}{n}+1=\frac{\beta y}{c n} \\
\alpha \mu \frac{y}{k}+\frac{r}{c}=\frac{\alpha y}{c k} \\
\dot{c}=c[R-\rho-\pi] \\
\dot{c}=c[r-\rho-\delta] \\
\frac{y}{c}+\mu d^{\prime}(1) y=\gamma \rho\left(\pi-\pi^{*}\right)-\gamma \dot{\pi} \\
y=k^{\alpha} n^{\beta} \\
\dot{k}=y-\delta k-c
\end{gathered}
$$


Thus far, we have the above seven equations in seven unknowns $\{c, r, y, k, n, \mu, \pi\}$. An additional equation determining $R$ will be presented when we discuss monetary policy below.

Next, use (39) to solve for $\mu$ :

$$
\mu=\frac{\beta y-c n}{\beta c y}
$$

Also, define $\phi=d^{\prime}(1)<-1$. We may use (44) to substitute out $y$, (46) to substitute out $\mu$, and restating (42) given (41), the system becomes (41) and

$$
\begin{gathered}
\beta r k=\alpha n c \\
r-\delta=R-\pi \\
\dot{\pi}=\rho\left(\pi-\pi^{*}\right)-(1+\phi) \frac{k^{\alpha} n^{\beta}}{\gamma c}+\frac{\phi n}{\gamma \beta} \\
\dot{k}=k^{\alpha} n^{\beta}-\delta k-c
\end{gathered}
$$

This completes the derivation.

Proof of Theorem 1: By inspection, one eigenvalue of $A$ is $h_{3}$. The remaining two eigenvalues of $A$ are the eigenvalues of the submatrix $\hat{A}$ :

$$
\hat{A}=\left[\begin{array}{ll}
f_{1} & f_{2} \\
g_{1} & 0
\end{array}\right]
$$

Recall $g_{1}<0$ under an active policy and $f_{2}<0$ for every policy from (22) and (23). Then,

$$
\operatorname{det}(\hat{A})=-f_{2} g_{1}<0
$$

A negative determinant implies one explosive and one non-explosive eigenvalue of $\hat{A}$. Since $h_{3}>0$ by equation (26), $A$ has two explosive and one non-explosive root. With one predetermined variable $k$ and two jump variables $\pi, c$, the equilibrium is locally unique. Note that although $\dot{\pi}, \dot{c}$ do not depend on $k, \dot{k}$ does depend on $\pi, c$ because $h_{1}, h_{2} \neq 0$.

Proof of Theorem 2: From the proof of theorem 1, one eigenvalue of $A$ is $h_{3}$. Recall $h_{3}>0$. Also from the proof of theorem 1, the remaining two eigenvalues of $A$ are the eigenvalues of the submatrix $\hat{A}$. Under an active policy, $g_{1}>0$. Since $f_{2}$ is negative by (22),

$$
\operatorname{det}(\hat{A})=-f_{2} g_{1}>0
$$

Part (a): If $f_{1}>0$, then $\hat{A}$ has a positive trace and determinant. The dynamics of $(\pi, c)$ are governed by two explosive eigenvalues. Independent of the path of capital, the only equilibrium where inflation and consumption remain in a neighborhood of the steady state is $(\pi(t), c(t))=\left(\pi^{*}, c^{*}\right)$ for all $t$. 
Next, let us impose this necessary condition for an equilibrium on the law of motion for capital. Equation (27) becomes:

$$
\dot{k}=h_{3} \hat{k}
$$

Recall $h_{3}>0$. In any equilibrium where inflation and consumption do not explode, the capital path is explosive unless $k(0)=k^{*}$.

Part (b): If $f_{1}<0$, then $\hat{A}$ has a negative trace and a positive determinant. Both eigenvalues of $\hat{A}$ are non-explosive. Locally, any arbitrary pair $\left(\pi_{0}, c_{0}\right)$ is consistent with an equilibrium path for $(\pi(t), c(t))$ that converges asymptotically to $\left(\pi^{*}, c^{*}\right)$. The solution for an equilibrium time path of inflation and consumption is:

$$
\begin{gathered}
\hat{c}\left(t, \sigma_{1}, \sigma_{2}\right)=\sigma_{1} e^{r_{1} t}+\sigma_{2} e^{r_{2} t} \\
\hat{\pi}\left(t, \sigma_{1}, \sigma_{2}\right)=\frac{r_{1} \sigma_{1}}{g_{1}} e^{r_{1} t}+\frac{r_{2} \sigma_{2}}{g_{1}} e^{r_{2} t}
\end{gathered}
$$

where $r_{1}, r_{2}<0$ are the real eigenvalues of $\hat{A} .{ }^{10}$ Because both eigenvalues are non-explosive, $\sigma_{1}, \sigma_{2}$ are not restricted in order for inflation and consumption to be an equilibrium.

Using (51) and (52) to solve the differential equation for capital (14), we have:

$$
\hat{k}\left(t, \sigma_{1}, \sigma_{2}\right)=\frac{\sigma_{1}\left(h_{1} r_{1} / g_{1}+h_{2}\right)}{r_{1}-h_{3}} e^{r_{1} t}+\frac{\sigma_{2}\left(h_{1} r_{1} / g_{1}+h_{2}\right)}{r_{1}-h_{3}} e^{r_{2} t}+\varphi_{k} e^{h_{3} t}
$$

To rule out explosive paths, we set $\varphi_{k}=0$. Let $\sigma_{1}$ take on an arbitrary value $\bar{\sigma}_{1}$. The second free parameter $\sigma_{2}$ must be selected in order to satisfy the initial condition on the capital stock:

$$
\hat{k}\left(t, \bar{\sigma}_{1}, \sigma_{2}\right)=k_{0}
$$

An active policy where $f_{1}<0$ implies a continuum of equilibria that converge asymptotically to the steady state.

Solving Experiment 2: Defining $\hat{x}=x-x^{*}$, the differential equations are

$$
\begin{gathered}
\dot{\pi}=f_{1} \hat{\pi}+f_{2} \hat{c}+f_{4} \varepsilon(t) \\
\dot{c}=g_{1} \hat{\pi}+g_{4} \varepsilon(t) \\
\dot{k}=h_{1} \hat{\pi}+h_{2} \hat{c}+h_{3} \hat{k}+h_{4} \varepsilon(t)
\end{gathered}
$$

Since policy is passive, there is one stable eigenvalue of the dynamic system according to theorem 1 . Let $r_{1}, r_{2}$ be the eigenvalues of the system given by (53) and $(54 \mathrm{a})$, and $r_{3}$ is the additional root gotten by looking at the three variable system. It is straightforward to show that $r_{3}=h_{3}$. Without loss of generality,

\footnotetext{
${ }^{10}$ Replicating the argument for imaginary eigenvalues is straightforward.
} 
let $r_{2}>r_{1}$. It is straightforward to show that $r_{1}$ is the only negative root of the three variable system.

Rearranging (54a),

$$
\hat{\pi}=\frac{1}{g_{1}} \dot{c}(t)-\frac{g_{4}}{g_{1}} \varepsilon(t)
$$

Taking the time derivative:

$$
\dot{\pi}=\frac{1}{g_{1}} \ddot{c}(t)-\frac{g_{4}}{g_{1}} \varepsilon^{\prime}(t)
$$

Using (53), we have a representation for $\hat{c}$ that depends only on time:

$$
\hat{c}(t)=\frac{1}{f_{2}}\left[-\frac{f_{1}}{g_{1}} \dot{c}(t)+\frac{1}{g_{1}} \ddot{c}(t)-\frac{g_{4}}{g_{1}} \dot{\varepsilon}(t)+\left(\frac{f_{1} g_{4}}{g_{1}}-f_{4}\right) \varepsilon(t)\right]
$$

Rearranging,

$$
\ddot{c}-f_{1} \dot{c}-g_{1} f_{2} \hat{c}=\left[g_{1} f_{4}-f_{1} g_{4}\right] \varepsilon+g_{4} \dot{\varepsilon}
$$

Recalling the definition for $\varepsilon$,

$$
\ddot{c}-f_{1} \dot{c}-g_{1} f_{2} \hat{c}=\left(g_{1} f_{4}-f_{1} g_{4}-\theta g_{4}\right) \bar{\varepsilon} e^{-\theta t}
$$

The non-explosive solution for $\hat{c}$ is then:

$$
\hat{c}(t)=\varphi_{1} e^{r_{1} t}+z_{2} e^{-\theta t}
$$

where $z_{2}=\left(g_{1} f_{4}-f_{1} g_{4}-\theta g_{4}\right) \bar{\varepsilon} /\left(\theta^{2}+f_{1} \theta-f_{2} g_{4}\right)$ and $\varphi_{1}$ is an undetermined coefficient. The expressions for $\hat{\pi}$ is:

$$
\hat{\pi}(t)=\frac{r_{1} \varphi_{1}}{g_{1}} e^{r_{1} t}-\frac{1}{g_{1}}\left[z_{2} \theta+g_{4} \bar{\varepsilon}\right] e^{-\theta t}
$$

Substituting (58) and (57) into (55), we have a non-homogenous first-order equation in $\hat{k}$.

$$
\dot{k}-h_{3} \hat{k}=\varphi_{1}\left[h_{1} r_{1} / g_{1}+h_{2}\right] e^{r_{1} t}+\left[h_{2} z_{2}+h_{4} \bar{\varepsilon}-\frac{h_{1}\left(z_{2} \theta+g_{4} \bar{\varepsilon}\right)}{g_{1}}\right] e^{-\theta t}
$$

or,

$$
\dot{k}-h_{3} \hat{k}=z_{3} e^{r_{1} t}+z_{4} e^{-\theta t}
$$

where $z_{3}, z_{4}$ are appropriately defined. The solution is:

$$
\hat{k}=\frac{z_{3}}{r_{1}-h_{3}} e^{r_{1} t}-\frac{z_{4}}{\theta+h_{3}} e^{-\theta t}+\varphi_{2} e^{h_{3} t}
$$

where $\varphi_{2}$ is an undetermined coefficient. Since $h_{3}$ is the third eigenvalue of the dynamic system, we know that $h_{3}>0$. We are interested in non-explosive equilibria; therefore, set $\varphi_{2}=0$ :

$$
\hat{k}=\frac{\varphi_{1}\left[h_{1} r_{1} / g_{1}+h_{2}\right]}{r_{1}-h_{3}} e^{r_{1} t}-\frac{1}{\theta+h_{3}}\left[h_{2} z_{2}+h_{4} \bar{\varepsilon}-\frac{h_{1}\left(z_{2} \theta+g_{4} \bar{\varepsilon}\right)}{g_{1}}\right] e^{-\theta t}
$$


We are left with a three variable system (58), (57) and (59), one undetermined coefficient $\varphi_{1}$ and one initial condition $k(0)=k^{*}$. Next, use $k(0)$ to pin down $\varphi_{1}$. Evaluating (59) at $t=0$, we have

$$
\varphi_{1}=\frac{r_{1}-h_{3}}{\left(\theta+h_{3}\right)\left[h_{1} r_{1} / g_{1}+h_{2}\right]}\left[h_{2} z_{2}+h_{4} \bar{\varepsilon}-\frac{h_{1}\left(z_{2} \theta+g_{4} \bar{\varepsilon}\right)}{g_{1}}\right]
$$




\section{Bibliography}

Benhabib, Jess, Stephanie Schmitt-Grohé and Martín Uribe (1999a), "The Perils of Taylor Rules," Journal of Economic Theory, forthcoming.

Benhabib, Jess, Stephanie Schmitt-Grohé and Martín Uribe (1999b), "Monetary Policy and Multiple Equilibria" New York University, manuscript.

Christiano, Lawrence, Martin Eichenbaum and Charles Evans (1997), "Sticky Price and Limited Participation Models of Money: A Comparison," European Economic Review 41, 1173-1200.

Christiano, Lawrence and Christopher Gust (1999), "Taylor Rules in a Limited Participation Model," NBER Working Paper 7017.

Clarida, Richard, Jordi Galí and Mark Gertler (1999), "Monetary Policy Rules and Macroeconomic Stability: Evidence and Some Theory," Quarterly Journal of Economics, forthcoming.

Dotsey, Michael, Robert King and Alex Wolman (1999), "State-Dependent Pricing and the General Equilibrium Dynamics of Money and Output," Quarterly Journal of Economics 114, 655-691.

Dupor, Bill (1999a), "Interest Rate Policy and Global Indeterminacy," The Wharton School, manuscript.

Dupor, Bill (1999b), "Interest Rate Policy and Investment with Adjustment Costs," The Wharton School, manuscript.

Goodfriend, Marvin and Robert King (1997), "The New Neoclassical Synthesis and the Role of Monetary Policy," NBER Macroeconomics Annual, 231-284.

Kerr, William and Robert King (1996), "Limits on Interest Rate Rules in the IS-LM Model," Federal Reserve Bank of Richmond Economic Quarterly, spring.

Leeper, Eric and Christopher Sims (1994), "Toward a Modern Macro Model Usable for Policy Analysis," NBER Macroeconomics Annual 1994, 81-117.

McCallum, Bennett and Edward Nelson (1997), "An Optimizing IS-LM Specification for Monetary Policy and Business Cycle Analysis," NBER Working Paper 5875 .

McCallum, Bennett and Edward Nelson (1999), "Nominal Income Targeting in an Open-Economy Optimizing Model," Journal of Monetary Economics 43, 553578 . 
Rotemberg, Julio (1996), "Monopolistic Price Adjustment and Aggregate Output," Review of Economic Studies 49, 517-531.

Rotemberg, Julio and Michael Woodford (1997), "An Optimization-Based Econometric Framework for the Evaluation of Monetary Policy," in NBER Macroeconomics Annual (Ben Bernanke and Julio Rotemberg, Eds.) 297-346.

Rotemberg, Julio and Michael Woodford (1998), "Interest-Rate Rules in an Estimated Sticky Price Model," in Monetary Policy Rules (John Taylor, Ed.), forthcoming.

Taylor, John (1993), "Discretion versus Policy Rules in Practice," CarnegieRochester Series on Public Policy 39, 195-214.

Woodford, Michael (1996), "Control of Public Debt: A Requirement for Price Stability," NBER Working Paper 5684.

Woodford, Michael (1998), "Doing Without Money: Controlling Inflation in a Post-Monetary World," Review of Economic Dynamics 1, 173-219. 
Dupor

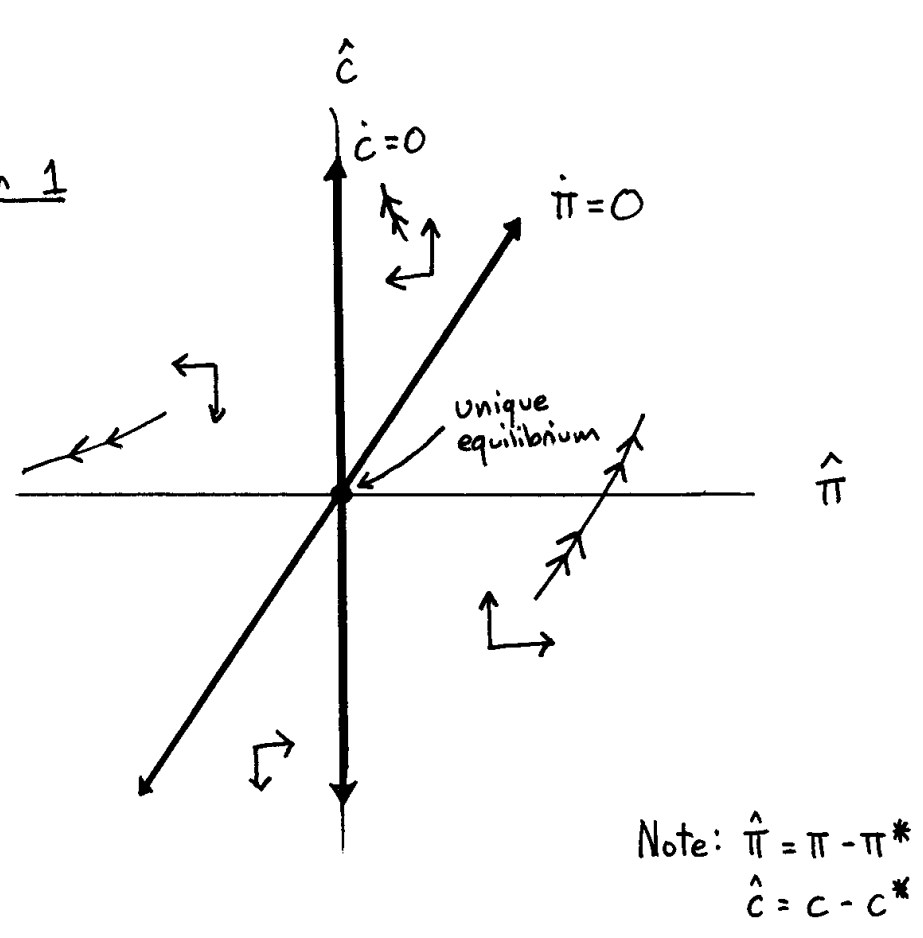

$10 / 21 / 99$

Diagram 2

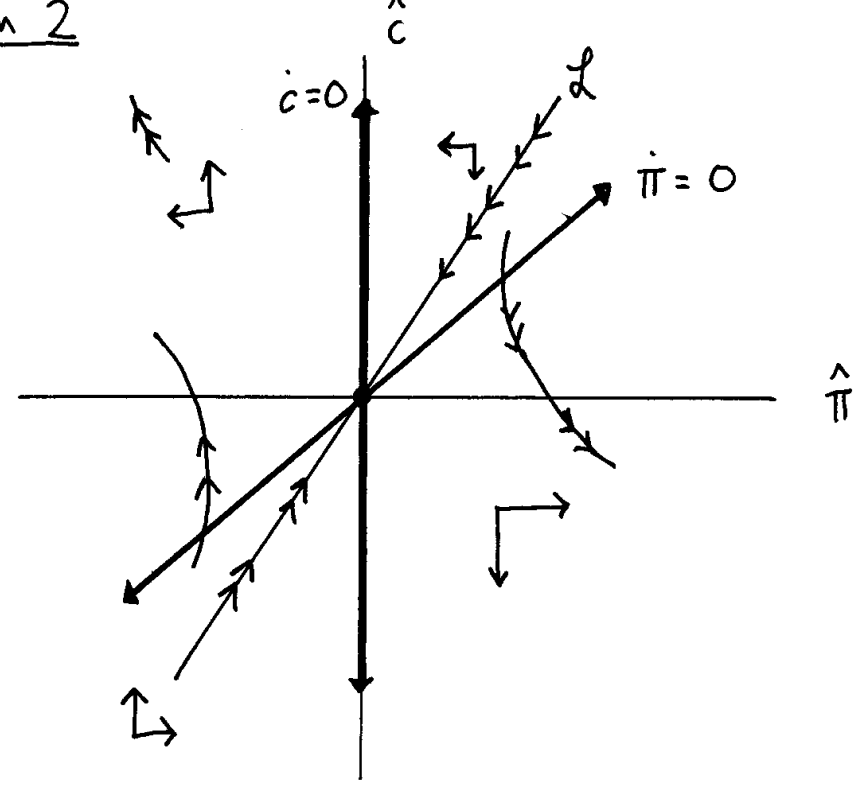


Dupor
Invest

10/21/99

Diagram 3

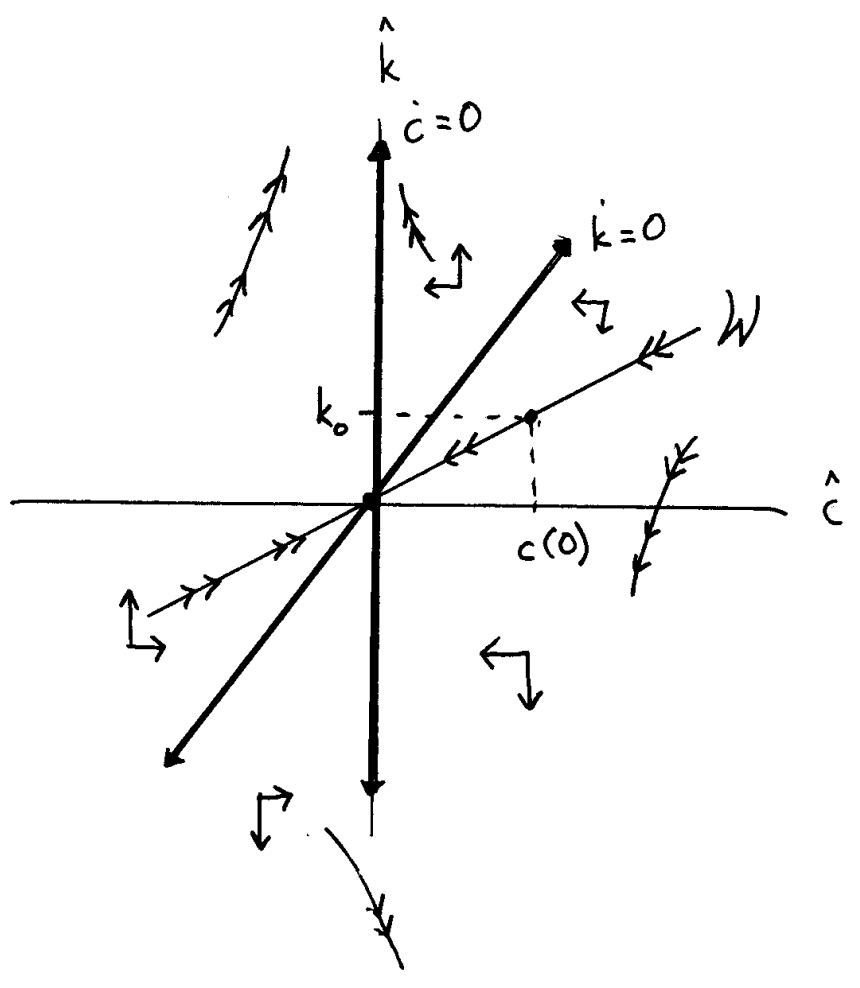

